\title{
Prospective teachers' difficulties in interpreting elementary phenomena of electrostatic interactions: Indicators of the status of their intuitive ideas
}

\author{
CRIADO, A.M. y GARCÍA-CARMONA, A. (2010). Prospective teachers' difficulties in \\ interpreting elementary phenomena of electrostatic interactions: indicators of the status of \\ their intuitive ideas. International journal of science education, 32(6),769-805.
}

\begin{abstract}
Student teachers were tested before and after a teaching unit on electrostatic interactions in an attempt to consider their intuitive ideas and concept development. A study was made of student's explanations of basic interactions: those between two charged bodies, and those between a charged body and a neutral body. Two indicators of the cognitive status of the explanations were investigated: 'context dependence' and 'certainty or confidence index'. This allowed cognitive comparisons to be established between the explanations of different electrostatic interactions, and between the degrees of difficulty they represent for satisfactory conceptual evolution. The greatest difficulties were found with explanations of the phenomena of electrostatic induction. The sample consisted of 52 students of primary school teacher education that participated in a teaching unit designed to overcome these obstacles.
\end{abstract}

Keywords: teaching and learning electrostatics, status indices, students' conceptions, obstacles to learning.

\section{INTRODUCTION}

The need to consider students' everyday or prior conceptions when designing and implementing a teaching unit is one of the most widely accepted premises in science teaching (Buty, Tiberghien and Le Maréchal, 2004; Lijnse and Klaassen, 2004). There are numerous opportunities to put this into practice (e.g., Hewson, Beeth and Thorely, 2003; Carrascosa, 2005). They all, however, require the teacher to have had the appropriate professional education to be able to determine exactly what learning is demanded for the topic being taught (Leach and Scott, 2002). The next step requires analyzing how these initial ideas interfere with or impede the relevant scientific concepts. This will help establish the most suitable teaching strategies for each case. It was precisely this that we set out to do with our students of primary teacher education when we teach them the notions of electrostatics.

Reviewing the literature, one readily finds studies devoted to the more abstract concepts of electrostatics, but not those that deal with the more elementary notions. One might hence be led to think that these notions cause no problems. We have found, however, that our students' difficulties do not start with the more advanced concepts of electrostatic field or potential, but much earlier. This was the reason that led us to inquire into our students' notions about the elementary concepts of electrostatics (Criado 2000). To this end, we used a specifically designed teaching unit to help us examine how those notions evolve. This research line started several years before with several exploratory studies. Some of its many results will be presented in this communication.

In previous work, we have shown how students identify electrostatic phenomena in their everyday context (Criado and Cañal, 2002a), and have described the obstacles they usually come across when they are learning the topic (Criado and Cañal, 2002b).

To investigate the greatest obstacles, we tested the differences in certain indicators of the status of those prior ideas. For example, with the help of multivariate analysis, we studied the 
extent to which the ideas are interrelated, analyzing the corresponding indicator-'degree of structure of prior ideas in models' (Criado and Cañal, 2000).

We then focused especially on status indicators (which were described in Criado and Cañal, 2003 ) related to the concepts of 'charged body' and 'neutral body'. That study confirmed that the students may interpret labels such as 'charged body' or 'neutral body' differently from the accepted scientific meaning, and also showed that several different ideas may coexist in their minds.

Given this description of the difficulties with the 'charged' and 'neutral' concepts, the central point of the present work is 'interactions' between charged/neutral bodies. Student teachers were tested before and after a teaching unit on electrostatic interactions in an attempt to determine their intuitive ideas and concept development. Status indicators of their different explanations of electrostatic interactions were estimated in order to identify the greatest obstacles to learning.

\section{THEORETICAL FramEWORK}

One of the basic components of a teacher's professional knowledge is pædagogical content knowledge (Lee and Luft, 2008; Nilsson, 2008; Shulman, 1986, Van Driel, Verloop and de Vos, 1998). This includes such skills as: (a) the ability to anticipate the difficulties which pupils may have, (b) the valuation of the kind of obstacle that these usually represent, and (c) planning suitable strategies to address them. Therefore, the study of prior ideas, which is closely related to the planning and implementation of teaching, constitutes a fundamental element of teachers' professional knowledge.

In the present state of advances in Science Education, the catalogue of alternative conceptions on almost any topic of science is now well established (see for example Driver, Guesne and Tiberghien, 1992). The challenge now is to go a step farther and determine which of them really pose the greatest obstacles to learning in the light of what we know about the nature of students' prior ideas. In teaching science, one starts from the hypothesis that a student will have achieved meaningful and appropriate learning if he or she is able to: (a) interpret it in different contexts, (b) apply it to the analysis of new problem situations, and (c) distinguish the contexts in which it is applicable from those in which it is not.

\section{The nature of students' prior ideas about scientific concepts}

The hypothesis that students' prior ideas are unrelated, ad hoc constructs that had helped the students get through tests of knowledge at school would today seem very weak. Instead it is known that there exist general patterns of intuitive reasoning in the various fields of science (e.g., American Institute of Physics [AIP], 1998; Charrier, Cañal and Rodrigo, 2006; Driver, Guesné and Tiberghien, 1992; Pfund and Duit, 1998; Tiberghien, Leornad and Barojas, 1997, 1998; Taber, 2002; Wood-Robinson, 1995). It is also known that, across different cultural and sociological milieux, the conceptions of students of a certain age about any given topic of science reduce to a prototypical set of notions which in a certain sense are analogous to the ideas that formed part of the historical and epistemological evolution of that area of scientific knowledge (Furió, Guisasola and Zubimendi, 1998; Matthews, 1990; Padilla and Furió-Mas, 2008; Seroglou et al., 1998).

Theories of conceptual change (Hewson and Thorely, 1989; Hewson, Beeth and Thorely, 2003), with their central concepts of the 'status' of ideas and 'conceptual ecology', have provided new perspectives for research into conceptions. 
In the Spanish context, there has long been a call to consider the characterization of intuitive ideas in greater depth (Oliva, 1997, 1999a). The notion of the status of ideas from the theory of conceptual change can contribute to this because it allows the nature of students' intuitive ideas to be specified and quantified. This concept has been defined as a measure of the degree of the intelligibility, plausibility, and utility for students of different concepts (Hewson and Thorely, 1989). Oliva (1997) suggests that one approach operationally would be to study indicators of how strongly or deeply rooted prior ideas are in the minds of students, and to seek hypotheses that might explain the behaviour of these indicators.

An individual's alternative conceptions have an implicit structure (albeit of a certain fuzzy or diffuse nature) of diversity and coexistence, and their activation involves a degree of uncertainty (Monk, 1995; Oliva, 1999a). This means that there can coexist in the cognitive structure of the same individual multiple alternative frameworks which apply to the same conceptual area. This implies a multifaceted nature of the cognitive structure, as concluded by Taber (2000) from a review of the literature and that author's own data. According to Taber, it is not a case of the student's everyday and academic contexts employing different zones of his cognitive structure. Rather the different frameworks compete with each other in the single zone of the abstract ideas corresponding to the domain of abstract scientific knowledge.

It follows therefore that when a student is asked to explain a phenomenon, the various explanations which he finds plausible and which coexist in his mind come into competition with each other. The response which is finally activated is the result of this cognitive conflict. The explanations may be based on descriptive and directly observable features. But also his prior ideas may be based on fragments of scientific knowledge, valid in another context, but here evoked inappropriately, perhaps because no consideration was given to the scope of their application (Taber, 2000), or because of the difficulty of integrating knowledge from different scientific fields (Taber, 2008). For example, we observed that the same student can find various different meanings of 'charged body' and 'neutral body' simultaneously plausible. Indeed, this was the case in half of the group of students that we studied. Thus, a student may believe that the label 'charged' can mean 'imbalance of positive - negative particles', but also that 'its particles are shaking about'. Consistently, the same student may identify 'neutral' with 'balance of positive and negative charges', and at the same time believe that 'its particles are not shaking about, but are staying still'. And some students may also find that all these conceptions are coherent with the idea that in a 'neutral body there are no electrical particles at all - electrical particles are created with the help of some sort of energy'.

This multiplicity of interpretations led us to inquire into how deeply rooted the different ideas are. To this end we used the indicators of their status that will be described in the following paragraphs.

\section{Context dependence}

Given the foregoing, it is clear that the patterns of reasoning students use in different learning situations could be considerably influenced by the specific task that has been put to them. Hence, since the final responses they give may also depend on that task, such responses are said to be 'context dependent'. Palmer (1997), for example, studied the effect of changing the context on the reasoning of students solving problems related to the forces acting on bodies moving in a straight line. That author noted that the 'identification of a deceleration' is closely linked to the direction of movement, and that students refer to it more in questions of horizontal rather than vertical motion. Recently, Teichert, Tien, Seth and Rickey (2008) have studied the effects of context on students' molecular-level ideas, showing the different forms of reasoning activated in the context of conductivity and elevation of the boiling point.

In electrostatics, we have seen that a student who observes that electrification is produced by 
contact and pressure may identify 'charged' with what a physicist would describe as 'neutral polarized'. But for the same student, 'charged body' may mean that 'its particles have a greater speed of agitation' if the electrification was produced by friction.

\section{The certainty index}

The hypothesis that prior ideas are implicit in character, and therefore fairly unconscious, suggests that they can not be defined in 'all or nothing' terms. Instead they seem necessarily fuzzy in nature (Monk, 1995). This would explain why students hesitate about the validity of their initial thoughts when explaining a phenomenon, instead of defining themselves with any firmness. One hence speaks of students' conceptions being more or less 'plausible' than others.

According to the action guidelines proposed by Hewson et al. (2003), classroom actions should include components that lead students to make explicit the extent to which they know and accept an idea. Then, when they are explaining some phenomenon, the teacher can determine the 'certainty' that they are expressing in those explanations. For example, the teacher might simply request them to indicate on some ordinal scale how sure they are about their response (Oliva, 1999b). This 'certainty index' of an idea can be related to the 'plausibility' of the explanation they are giving, and would be an indicator of the idea's 'status', i.e., of how deeply rooted it is, how plausible the student really finds it, and the depth to which he is able to understand it.

\section{Other indicators of the status of prior ideas}

A student's conceptions about a scientific phenomenon do not appear to be a disperse set of entities. Rather they are organized into definite patterns, as reflected in the literature cited above.

In addition to the connections between the alternative conceptions themselves, the type of link established with other elements of their partial scientific knowledge (Taber, 2008) may be decisive in triggering one or another set of ideas when students have to interpret some phenomenon. For example, when we asked students what would be the result of the electrification by rubbing a metal held in the hand, we obtained two prototypical associations. The student who evokes the idea of the metallic bond as 'strongly bound electrons' predicts that the metal will not be electrified. The student who evokes the idea of 'free electrons', however, predicts the contrary result. Hence the form and the degree to which students' ideas are structured and grouped is another way of determining how deeply rooted they are in their minds.

In this way, one can discover which of their pre-existing ideas the students find very compelling (with a high status in their minds). These should therefore be taken into account when one is teaching.

In this process, if we manage to get the students to gain awareness of the intelligibility, plausibility, and usefulness of their own and their colleagues' ideas, we shall be on the right track to achieve effective instructional strategies for conceptual change. In this regard, we have followed the metacognitive strategy used by Jimenez-Aleixandre (1992). In the teaching process, the ideas that are revealed by a pre-test are first discussed in small groups. They are then analyzed in a joint session of all the groups. With this approach, the path to the final selection of the most appropriate explanatory ideas and conclusions has passed through a critical examination of all the competing possibilities. It has also involved reflection on and feedback to the learning process itself.

The analysis of how the status of intuitive conceptions evolves from their first manifestations 
to the end of the teaching process can provide clues as to which educational improvements should be implemented.

\section{Research Methods}

The multiplicity of alternative conceptual schemes in a given student can be identified by means of longitudinal case studies over some time period (Taber, 2000). The other extreme is to perform a cross-sectional study, collecting data from many students simultaneously, and constructing an extensive inventory of their ideas. Our methodological approach possesses intermediate characteristics.

Our objective was to put into practice the idea of teachers who carry out research in their classroom (action research) with the aim of using the results to improve their actual teaching (Keevs, 2003). Also, by collecting data from all the students of the group before, during, and after the teaching process, we believe that, as the results emerge, they can have an instant positive impact on the learning of the participating students.

\section{Sample}

The study involved 52 science-specialist undergraduate trainee primary teachers in a 3-year program of initial teacher training to which we had access at that time (sample of convenience). Even though this group was initially quite large, the final sample analyzed was reduced to 52 students - those who participated in all the phases of the study. Their scores in the university access examination had ranged from 6.4 to 7.4 (out of 10). More than half of the sample had studied Physics in school in the previous academic year, although we found no statistically significant relationship between these data and the test answers.

\section{Phases of the study}

The overall empirical study was divided into two phases (Criado 2000):

\section{Preliminary exploratory studies}

First, a series of exploratory tentative studies were conducted during various academic years with student samples different from that of the definitive study. These formed part of a project of innovation aimed at teaching electrostatics at the university level. In this phase we designed and validated the teaching unit and the tools to identify the prior ideas (test and activity answer sheets), and drafted a list of conceptions.

Definitive or ultimate study

Finally, in the definitive study, the pre- and post-tests were applied at the beginning and end of the implementation of the teaching unit in order to determine its effectiveness and obtain the corresponding data for later analysis.

\section{Temporal development of the definitive study}

The sequence followed in the definitive study, with the sample and results reported in this present paper, was :

\begin{tabular}{|c|c|c|c|c|c|}
\hline $\begin{array}{l}\text { Introductory } \\
\text { experiments }\end{array}$ & Pre-test (Y) & $\begin{array}{l}\text { Teaching unit } \\
\text { (electric charge }\end{array}$ & $\begin{array}{l}\text { Beginning of } \\
\text { next unit (E}\end{array}$ & $\begin{array}{l}\text { Post-test } \\
\text { (X) }\end{array}$ & $\begin{array}{l}\text { Post-test } \\
\text { (Y) }\end{array}$ \\
\hline Pre-test (X) & & & $\begin{array}{l}\& 2 \text { weeks } \\
\text { holiday }\end{array}$ & & \\
\hline
\end{tabular}




\begin{tabular}{|c|c|c|c|c|c|}
\hline Day 1 & Day 2 & $\begin{array}{c}5 \text { weeks } \\
(20 \mathrm{~h})\end{array}$ & 2 weeks & Day 1 & Day 2 \\
\hline
\end{tabular}

A test (Annex 1) was applied, preceded by six simple electrostatics experiments (pre-test) using materials familiar to the students. The test questions dealt with those experiments.

The test was divided into two parts (X and $\mathrm{Y}$ ) with homologous questions. These were given on two consecutive days so that the answers to the questions of Part $\mathrm{X}$ did not interfere with their counterparts in $\mathrm{Y}$.

The teaching unit (examples in Annex 2) was carried out over 5 weeks. Two weeks after the end of the unit, and unexpectedly, the same test divided into its two parts (post-test X and Y) was given, again on two consecutive days. The Easter break was the week before this posttest, which could have had a positive effect of disconnection of the students' minds with respect to the concepts concerned.

\section{Tools for prior idea identification}

In synthesis, for each student there were individual data from two tests and the individual answer sheets of the activities carried out by groups during the teaching unit.

In the exploratory studies, we sought the way of obtaining the richest information possible about the students' ideas. The aim was for their responses to not merely consist of descriptions of what they had observed, as had been the case in our earlier studies and in the literature that we reviewed. Instead we wanted them to support their explanations on the basis of their knowledge of the nature and behaviour of matter at a microscopic scale.

These exploratory studies were used to prepare the final version of the test, also taking into account the opinions of five former students. It was then tried out with students of the same level and subject, but in academic years previous to that of the final study.

The teaching unit was also then almost in its final form. Minor modifications were made in the course of its implementation. These were either as immediate adaptations to the needs detected during the implementation, or in light of the results yielded by the pre-test. Finishing touches were made to the instruments' validity by submitting the test to the critical appraisal of twelve university teachers (six of physics, and six of science education) who acted as 'critical friends' not participating in the project. Two of these physics teachers and two of the science education teachers also analyzed the teaching unit. The process consisted of reaching consensus on how to improve the final wording, and on what should be the expert reply to the tasks and questions put to the students.

The aim of dividing the test into two homologous parts was to investigate how changing the example changed the students' kind of reasoning, or at least their level of confidence in their responses. To this end, the tests included a Likert scale of responses. (The results that we shall present in this work are for only three pairs of items of the whole test.) The students were asked to explain (with phrases and drawings) three pairs of elementary experiments that will be described below. These experiments were performed in class as a demonstration moments before applying the pre-test.

The progress of the teaching unit's activities was monitored by analyzing the previously designed 'open answer sheets' (Criado and Cañal, 2002b). The students completed these sheets individually, even though they carried out the activities in groups. The teacherresearcher collected these sheets at the end of each activity.

After the corresponding data were recorded, the results were taken into account in the next class. On the whole, this information involved making some change to the activities, as well 
as a class discussion led by the teacher for the students to reconsider the questions that remained unclear and to recapitulate and strengthen the principal ideas.

The responses to the tests and class activities were first analyzed by the teacher-researcher who was implementing the study in her classroom. They were also subjected to a second analysis by the same teacher (intra-referee analysis) two months later. The cases of doubtful responses were analyzed in discussion with one of the 'critical friends' before their final classification.

\section{Demonstration experiments performed before applying the test}

As noted above, various experiments were performed before applying the first prior idea test (pre-test X). In doing these experiments, care was taken to show that, before their electrification, there was no interaction between the objects used (between a ball-point pen and pieces of paper; between the pen and a pith-ball electroscope; between a sheet of plastic or transparency and pieces of paper; between the plastic and the ball electroscope; or between four strips of adhesive tape labelled A-D).

The experiments included various procedures of electrification, including electrification by contact and by friction (Criado et al., 1997). The types of experiment were the following:

1) The first type of experiment started with neutral objects whose mutual firm contact - but without rubbing - resulted in oppositely charged pairs of objects when they were separated. Then it was seen whether there was any interaction between the two. In particular, these experiments were:

* A sheet of plastic (transparency) and a sheet of paper which were pressed together, and then separated.

* Two pairs (A-B and C-D) of strips of adhesive tape (Scotch brand), about $20 \mathrm{~cm}$ long, which were mutually electrified by sticking a side with glue onto the other glue-less side. They were then separated, and brought up close to each other to check the interactions between any pair.

* Two strips of adhesive tape, freshly cut from the roll, which always repel each other.

2) The second type of experiment dealt with the classical case of frictional electricity when an object is rubbed with a cloth. Only the electrification of the object is checked:

* A plastic ball-point pen rubbed with lining fabric (100\% polyester).

* A transparency rubbed with the lining fabric.

3) The last type of experiment was to see how objects that had previously been electrified also attracted lightweight objects (which had not been given any treatment and which we labelled as neutral). After coming into contact with the electrified objects, these lightweight objects were sharply repelled:

* The typical case of the pen electrified by rubbing and thin pieces of paper (cigarette papers).

* The electrified pen and a pith-ball electroscope.

* A transparency electrified by pressure and thin pieces of paper.

* The electrified transparency and a pith-ball electroscope.

Without giving the students clues to the interpretation of the phenomena, and limiting ourselves to emphasizing the description of what was happening, the goal was to provide them with an abundant empirical basis of different situations. We then selected the three pairs of experiments summarized in Table 1. They were the object of the homologous questions of the test, which included, for each case of interaction, the two contexts or homologous 
examples (see Annex 1).

------- Insert about here Table 1

Table 1. Summary of the format of the homologous questions (with change of example or context).

\section{Statistical techniques}

Descriptive statistics were used to analyze all the data, including those of the study of the 'degree of certainty' and 'resistance to change after teaching' of the conceptions.

Also, to study the 'context dependence' indicator, we applied Pearson's chi-squared independence test (Sánchez Carrión, 1995). This test can be used to check whether two nominal variables are independent, or conversely whether there exists some association between them. In the present study, if we find that our two variables (homologous questions) are statistically associated (the responses coincide even when the example is changed), we will say that the students' explanations are context independent.

\section{The Questions Addressed in the Study}

The questions that we set out to investigate by asking students to interpret phenomena associated with elementary electrostatic interactions (attractions and repulsions) were the following:

Before and after the planned teaching-learning sequence

* What inadequate prior ideas compete with the scientific response?

* What is the students' degree of certainty in their explanations?

* What is the degree of context dependence of the students' response?

During the teaching-learning sequence

* What changes in their ideas and reasonings are observed during the teaching-learning sequence?

As a result of the foregoing information:

* Which ideas are most resistant to change after the teaching-learning sequence?

The responses were analyzed using the aforementioned indicators of the status of the students' ideas. This allowed us to identify those ideas which had the highest 'status', i.e., those most firmly entrenched in the students' minds.

\section{WORKING HYPOTHESES}

\section{Which prior ideas might one expect to find?}

We established the hypothesis that guided the design of the instruments to detect the prior ideas following an analysis of similar studies on the topic (Furió and Guisasola, 1998, 1999; Furió et al., 2003; Meneses and Caballero, 1995; Pontes and Pro, 1998), and taking into account the results of the exploratory studies that we had carried out. We found that the best way to obtain the students' responses was with the formulation of two questions:

A) Given a charged body, how can one explain this 'electrical state' at a microscopic level?

B) For two bodies to interact electrically, what do their 'electrical states' have to be like? 
The results described in the literature cited above and of our exploratory studies led us to refine the hypothesis concerning the possible responses, as will be described in the following paragraphs.

With respect to Question A, the responses seemed to rely on bits of knowledge learnt at school dealing with electricity or the corpuscular nature of matter. (Occasionally they were related to an identification of magnets with electric dipoles.) The students had constructed inappropriate relationships between these pieces of knowledge, and also associated them inappropriately with the electrical phenomena. The commonest explanations were of four types:

A1) There is an imbalance in the number of positive particles and negative particles, with one of the two signs predominating. (The scientific explanation.)

A2) There is a reorganization of charged particles which accumulate in a bipolar way in the material. (A physicist would use the label 'polarized' for this electrical state.)

A3) Particles are "shaking around" (in electrification by friction). (Thermal motion is linked with electricity.)

A4) Electrical particles are created during the electrification process. (Particle creation, even justifying this as a kind of 'conversion of mechanical energy, or heat, into electricity', and making it fit well with the foregoing models.)

With respect to Question B, it should be borne in mind a priori that even when students actually observe phenomena themselves, there may still arise the difficulties and obstacles to inductive reasoning that were detected by Brincones and Otero (1994). In this case, when the students used a series of teaching card aids describing experiments of electrostatic attraction and repulsion as a basis for their inductive reasoning, they failed to draw the logical conclusions. Principally, however, they have usually readily incorporated the rule 'opposite poles attract, and like poles repel' into their intuitive thinking. This set of conceptions is so solidly entrenched that it even constitutes an obstacle when it comes to considering the interaction between an electrically neutral object and another that is charged. Given that intuitive rule, and using the verbal labels that the students used, the three possible interpretations that they illustrated by means of phrases and drawings were:

B1) There necessarily has to be a certain 'symmetry' (both charged or both neutral).

B2) It is a case of 'asymmetrical' situations (one charged and one neutral).

B3) Both types of situation may be involved.

\section{What strategies should be followed in a teaching unit in order to foster conceptual evolution?}

In addition to the theoretical framework outlined above, in what follows we shall present some further hypotheses that served as fundamental support for the design of the teaching unit used in the present study. These hypotheses resulted from our continuing reflection and action research work in exploratory studies over several years.

Firstly, we would note that, to construct scientific concepts by means of teaching, specific facts and data must be taken as points of reference (Cañal, 1999). A prospective teacher should then have enough background knowledge to be able to approach a suitable level of professional know-how.

For the teaching process, of particular interest is the model of learning by inquiry into problem situations, in which students can construct their knowledge under the guidance of the teacher (Lee, 2003, Porlán and Martin del Pozo, 2002). Within this model, and relating to electricity, there are the studies of Fischer and von Aufschnaiter (1993), Meneses (1999), 
Pontes (1999), and Furió et al. (2003), among others.

With respect to the problem situations, those of a qualitative nature are considered to be potentially more fruitful educationally (Tao, 2001). This is because their solution in many cases involves selecting the appropriate concepts and principles and their relationships. In contrast, algorithmic exercises do not require this application of the intellect. Instead, the student just has to search his memory for a formula into which to mechanically plug in the problem's numerical data. He will then get the numerical solution without any assurance that he understood the theory of electrostatics behind it (McMillan and Swadener, 1991).

Therefore, setting qualitative problems to be solved collectively through the confrontation of ideas and their subsequent co-construction, i.e., by negotiating agreement, appears most often to lead to appropriate learning solutions.

There are many ways of putting all these ideas into practice. The choice will be influenced by the practical knowledge that each teacher has. In our case, we designed a teaching unit consistent with the above ideas, using the following criteria:

* Transform the wording of problems into questions that are suggestive of concrete situations.

* Relate physical concepts to aspects of interest expressed by the students, and to re-interpret their everyday explanations. (Are there people who 'have got' electricity? Why do we sometimes get an electric shock when we close a car door? Why do glues 'stick'?)

* Start by dealing with the mutual electrification of pairs of initially neutral bodies, and with the observation of attraction and repulsion between charged bodies. These would be the first specific experiments with which to inquire into the students' prior ideas.

* Take care not to over-use electrification by friction in electrification experiments. The reason is that it suggests such ideas as 'heat can be converted into electricity'. It is better to focus on electrification by contact which leads to fewer alternative conceptions.

* Introduce electric charge as a property of matter after having presented electrification by contact as empirical support, and also introduce attraction and repulsion between charged bodies, but postpone phenomena of induction which are less intuitive.

* Provide data on real quantities of electric charge in known situations, either estimating them, or using the values available in such textbooks as those of Hetch (1987) or Feynman, Leighton and Sands (1987). (Charges of 10-8C in an electrified pith-ball electroscope; 10-6C in a $400 \mathrm{kV}$ van de Graaff generator; $20 \mathrm{C}$ in a lightning stroke from the clouds to the ground). Quantities, phenomena, and concepts can then be meaningfully related to each other.

* In the line suggested by Jimenez-Aleixandre (1992) and Hewson (2003), propose activities that give students the opportunity to go back over their responses to the questionnaires on their prior ideas and reason about their validity, instead of simply presenting the theoretical foundation without taking those responses into account. This demands: (a) working collectively and considering multiple solutions to every problem, (b) comparing all the solutions (an inventory of responses to the pre-test from the entire class), and (c) the students contrasting their own ideas with those of their colleagues, discarding - on the basis of collectively constructed logical arguments - the inadequate alternative ideas, and strengthening those which are appropriate.

* Plan sufficient experiments, with simple materials, that are movable to the school context and provide empirical support for the theory being studied (Criado et al., 1997). (For example, the illumination - visible in the dark - of a small fluorescent tube to detect the electricity of a charged body, (figure 1); or building a leaf or a pith-ball electroscope using household materials.)

* Propose activities of an optional type, anticipating varying degrees of interest and pace of 
work in the group class.

* Finish each block of activities and the teaching unit with a recapitulation, recalling the questions that were successfully resolved using the new concepts that were learnt, and including a list of problems that still had no satisfactory response with those concepts. This will show that new concepts need to be introduced in the next unit (Solbes and Martin, 1991). For example, recognizing the restricted scope of applicability of Coulomb's Law leads to understanding the usefulness of the concept of electric field when one wants to estimate electrostatic interactions in everyday systems, such as in the case of a charged storm cloud and the zone of air and land beneath it. Searching for some criterion to know how the charges will be distributed between two conductors that come into contact can help to see the necessity and usefulness of the concept of electrostatic potential. And one could continue in this way with most of the concepts that one wants to teach.

Having presented the questions addressed in the study and its working hypotheses, in the following section we shall detail its methodological aspects.

------- Insert about here Fig. 1 T.V. - Fluorescent tube -------

Figure 1. Electric discharge through a fluorescent tube held close to a TV screen.

\section{RESULTS AND Discussion}

The results will be presented following the first research questions, and the last question will be answered in the conclusions as a result of the foregoing information.

\section{What inadequate prior ideas initially compete with the scientific answer and what changes in the students' ideas and reasonings are observed during the teaching-learning sequence and post-test?}

We will answer these questions for each of the three electrostatic interactions studied. Figures 2-4 present a synthesis of the descriptive data obtained from the tests. They give the percentages of the explanations given for each type of interaction (in both contexts) before and after the teaching and learning process.

Figure 2 presents the reasonings given for the attraction between charged bodies ('c-c attraction'). It corresponds to the test question 'Why do the objects attract each other?' when using 'two strips of adhesive tape' (first context) or a 'transparency (sheet of plastic) and a paper sheet' (second context). Figure 3 presents the explanations given for the repulsion between charged bodies ('c-c repulsion'). It corresponds to the question 'Why do the objects repel each other?' in two contexts ('strips of adhesive tape' and 'transparency that repels a ball electroscope'). Finally, figure 4 gives the students' reasonings for phenomena of the interaction between a charged object and a neutral object ('c-n induction') in two contexts ('a ball-point pen that attracts thin pieces of paper' and a 'transparency that attracts a ball electroscope').

\section{c-c Attraction: Appropriate responses compared with alternative conceptions}

\section{Before teaching (pre-test)}

For the attraction between charged bodies, there were two predominant types of explanation. The appropriate explanation ( 1 * 'both bodies are charged with charges of opposite sign') was given by more than half of the students. It was followed by an idea that competed with the 
scientific explanation for the c-c attraction, the alternative conception: 'they are both neutral and polarized, with charges of different sign facing each other in the two objects, $|+-|++\mid$.

\section{During teaching and post-test}

During the teaching unit, in the 'response sheets' handed in by the students after discussing the answers to the prior-idea test and repeating the corresponding experiments, most of them $(86 \%)$ gave the appropriate response. The rest replied in vague terms, without drawing the electric charges. Nonetheless, on the 'response sheet' for a new experiment (to design a procedure to determine the sign of the charge acquired by different materials electrified by rubbing), the proper use of the rule 'unlike charges attract' rose to $96 \%$. We presume that the habit of doing experiments on their own and reflecting on them was having positive effects on their learning.

The post-test results showed very little expression of clearly defined alternative conceptions of this type of phenomenon.

Insert about here figure 2: c-c attractions diagram,

\section{c-c Repulsion: Appropriate responses compared with alternative conceptions}

\section{Before teaching (pre-test)}

With respect to repulsive interactions, the appropriate responses were commonest ( $1 *$ 'both objects have excess charges of the same sign') for the two contexts. The rival answers corresponded to different kinds of ideas and were less frequent. One was that 'both are neutral polarized, with charges of the same sign opposite each other', which we call 'inverse polarization, $|+-||-+|$ '. Another less frequent was that 'both are neutral without polarization', and that 'neutral state is what makes them repel each other' since 'if they were charged they would attract each other'. In sum, there appear more types of alternative conceptions competing with the scientific response in their interpretations of repulsion between two charged bodies than in the case of attraction.

\section{During teaching and post-test}

During the teaching unit, the experiments on repulsion between charged bodies were done in parallel with those on attraction. The answers (which were given on the same sheet) reflected this parallel treatment, and produced the same numerical results as those given above for the attractions c-c.

In the post-test results, although the appropriate response was the most frequent, the alternative conceptions indicating that a 'neutral object repels another neutral object' (responses 2 and 4 ) still had a presence of $8 \%$. The rest of the responses were a diverse set of vague phrases, which again suggests that interpreting repulsions still suffers from the difficulty of a greater multiplicity of competing ideas.

Insert about here figure 3: c-c Repulsions diagram

\section{c-n Induction: Appropriate responses compared with alternative conceptions}

\section{Before teaching (pre-test)}

In the case of c-n induction in the pre-test, responses of category $1 *$ (only one of the objects is charged, which causes a redistribution of charges in the neutral object, with an accumulation 
of charges of the different sign to that of the charged body in the part close to the latter) were given by very few students. Besides being a minority interpretation, this also had to compete with most alternative conceptions. These included the assumption that 'the two objects have different sign charges', which was the most frequent. In the rest of the conceptions, the two interacting objects were neutral, with some inappropriate type of polarization. For example, the alternative conception that was next in frequency assumed that the bodies attract each other 'because they are both neutral polarized', coinciding with the interpretation of the c-c attraction.

This discussion of the responses concerning the induction experiments leads us to the following two considerations:

* Most students focused on the fact that the two bodies attract each other, but neglect other aspects they observed when doing this kind of experiment, such as the different pre-treatment of the two objects, i.e., the process of electrifying only one of them. An important role was also played by an 'ad hoc' idea that we had not studied systematically - they believe in the existence of 'materials that are inherently charged with charges of one particular sign'. The case is that the wording of the rule 'charged bodies with charges of different sign attract' is converted into 'if two bodies attract, they are both charged and with charges of different signs'. This association between observation and interpretation is highly plausible for some students who do not question whether the reversal of the inference is logically valid.

* The students seeking a different explanation from fragments of previously learned abstract knowledge opted for: 'both bodies are neutral polarized'. Here there may have been an interaction between previously learnt concepts and a non-explicit rule of spontaneous reasoning: 'there has to be a certain symmetry between the states of the two bodies'. The two predominant explanations of c-n induction are both alternative conceptions which seem to emerge from a tendency towards 'symmetrical situations' on thinking about the electrical states of the two interacting bodies. This fits our first working hypothesis.

\section{------- Insert about here figure 4: Induction c-n diagram -------}

\section{During teaching and post-test}

On repeating these same experiments during the teaching unit, most of the students gave appropriate responses to both contexts. Nonetheless, for the case of new experiments on electrostatic induction, the results were mixed. This shows that the context effects of the typical experiments on electrostatic induction used in teaching can as much hinder as facilitate the search for appropriate explanations.

In particular, the students have evident difficulty in interpreting how a leaf electroscope works, (figure 5), even though they often have to use it (in empirical and pencil-and-paper tasks). In our case, the students worked both with homemade electroscopes that they constructed themselves and with the laboratory electroscope. In attempting to explain the visible opening of the leaves when a previously electrified object is brought up close, only half of the groups drew the separation of charges in the neutral electroscope. The rest considered that the experiment was identical to the one in which contact is made with the electroscope and charge is transmitted to it.

------- Insert about here figure 5 Induction - Leaf electroscope -------

Figure 5. When you bring a charged object up to a neutral leaf electroscope, why do the two 
leaves move apart?

Taking into account the results of other experiments on electrostatic induction that compared conductors and insulators (Park, 2001), one deduces that it is not easy to adapt the general explanation of induction to the case of the electroscope. The proper interpretation, even at an elementary level, is a relatively complex process (Fischer and von Aufschnaiter, 1993). This is because firstly there is asymmetry on the two sides of the plane around which separation of charges occurs - on one side there is a single piece that acquires charge of one sign, and on the other there are the two mobile leaves which share the distribution of the charge of the opposite sign. And secondly, the neutral object does not move en bloc (as in the experiments with the ball electroscope or with the thin pieces of paper), but rather the 'mobile effect' is observed only in the leaves moving apart from each other.

Hence, induction experiments which involve a leaf electroscope (Moore, 1991) are not so clear to interpret as we as teachers and the authors of physics textbooks would like to assume (even if no use is made of the concept of voltage).

Other electrostatic induction phenomena, such as the process of charging by induction, are found easier to assimilate. The interpretation of the process in which a person close to a van de Graaff generator $(400 \mathrm{kV})$ is electrified by induction (figure 6) seems to have been understood by most of the students. Perhaps the fact that it is an experiment that they actually live helps them to understand it. In particular, the student personally experiences having been electrified because first her hair stands out in the direction of the dome, and then there is a spark discharge when the student touches a colleague or some metallic object. They also saw that a small fluorescent tube which they held at one end emitted bursts of light when they came close to the generator (although this experiment was not interpreted in depth until the next unit dealing with electric fields and potentials).

Insert about here Figure 6: Induction - van de Graaff generator

Figure 6. Electrification of a person due to the influence of a nearby $400 \mathrm{kV}$ generator.

These facts, which they perceive in person, seem to help greatly to convince the students of the effects of electrostatic induction by a charged object on nearby objects. Indeed, all this seems to confirm the arguments of Heering (2000) that harmless electric discharges and the use of one's own body to experience static electricity provide effective support for reasoned explanations.

Understanding is also reinforced by the students talking about their own experiences of electric discharges, which they then interpret in class. However, in a pencil-and-paper activity which was very similar (but without directly experiencing any effect), only a little more than half of the groups drew correct conclusions. In this, they were asked to draw the electric charges on a tree subject to the electrostatic influence of a storm cloud charged with electricity of a given sign. It was expected that they would draw the electrostatic induction process by stages, since the theoretical interpretation was the same as their previous experiment with the van de Graaff generator. Many students, however, did not categorize them as similar situations.

Insert about here Figure 7: Tree and charged storm cloud

Figure 7. What distribution of charges will appear on the tree before a lightning discharge due 
to the build-up of static electricity in the clouds?

In the post-test at the end of the teaching unit, the most frequent responses to the electrostatic induction questions were the appropriate cases $\left(1^{*}\right)$. Nonetheless, some students maintained the idea that the observation of an attraction necessarily means that both objects are charged. Neither had there disappeared completely the alternative explanations that 'both objects are polarized' in one form or another.

Therefore, it was confirmed that, for the interpretation of the three electrostatic phenomena that we have described, the rule 'like charges repel, unlike charges attract' is firmly entrenched. For students, however, 'like charges' may have more than one meaning, and these meanings may be different from that of a physicist.

\section{What is the students' degree of certainty in their explanations?}

To determine how plausible the conceptions were for the students, we used a Likert scale of 1 ('not at all sure') to 5 ('completely sure') on which they scored their responses. The percentage of students who answered 'completely sure' or 'fairly sure' portrays this status indicator. Figures 8, 9, and 10 show the students' degree of certainty in their reasoning about c-c attractions, c-c repulsions, and c-n induction, respectively, before and after the teaching sequence. Percentages below $6 \%$ are not shown.

In the pre-test results before the teaching sequence, the fuzziness of much of the reasoning is reflected in the fairly low and uniformly distributed values of certainty with which the students would defend their explanations. Indeed, except for the c-c attractions, the status they assign to their prior and inappropriate ideas is similar to that of the appropriate answers. In particular, for the c-n induction, the reasoning 'the two objects have different sign charges' and 'they are both neutral polarized' are seen as considerably more plausible than the scientific answer.

In the post-test, there were high plausibility scores for the scientific answer, none being lower than $70 \%$. The certainty about scientific reasoning was higher for $\mathrm{c}-\mathrm{c}$ attractions and $\mathrm{c}-\mathrm{n}$ induction than for c-c repulsions. High plausibility scores for alternative conceptions were given only by a minority of students and only for c-n induction in the well-known plastic pen and pieces of paper context.

All this is indicative on the one hand of the resistance to change of some ideas in these individuals, and on the other of the degree of effectiveness of the teaching proposal for most of the students.

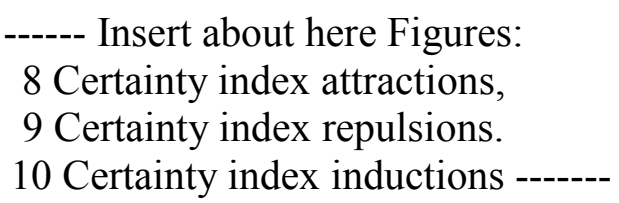

Up to now, we have commented on the results for the class as a whole. In the following, we will also show that the same individual student can use two different meanings in two situations that for the teacher would be homologous.

\section{What is the degree of context dependence of the students' responses?}

As we noted above, with the context dependence indicator we investigate whether contextual 
features - changing the example - can affect the reasoning a student applies to explain the same phenomenon. Contingency tables were constructed with the responses to each homologous pair of test questions. These show the degree of coincidence in crossing the variables (homologous questions). We also calculated the $\chi^{2}$ statistic, whose value allows one to reject or accept the hypothesis of independence of the variables.

Table 5 summarizes the contingency table data, showing: (1) the number of students $(n)$ who maintained the same response in both contexts; (2) the percentages represented by $n$ relative to the number of students who gave that response in each context $(\% X, \% Y) ;(3)$ the (global) percentage represented by $n$ relative to the total of 52 students $(\% g l o)$; and (4) the adjusted residual (a.r.) and the probability $(p)$. The repetitions of minority alternative conceptions are not included.

\section{Insert about here Table 2 Context dependence}

Table 2. Context dependence of the students' pre-test explanations.

One can infer from the results of Table 2 that before the teaching sequence (pre-test), the students' conceptions showed no context dependence (a.r. $>2$ or $p<0.05$ ) in four of the six electrostatic situations analyzed. I.e., a student's reasoning about a given phenomenon did not change when the example, or context, was changed. The responses that were least influenced by the context were those corresponding to an observed attraction between two objects, interpreting them (wrongly, for the induction) as that 'the two bodies have charges of different sign'.

In the c-c attractions, for example, both the appropriate explanation 'the two objects have charges of the same sign' and the alternative conception 'the two objects are neutral polarized' are context independent. Although the scientific answer was far more frequent, the conception that 'both objects are neutral' has a certain status as it was used consistently when the example was changed.

If the students' conceptions seem to change little with the context when they observe an attraction, with the observation of a repulsion - a less common phenomenon - their explanations might be less secure and less firmly entrenched. This would explain the change in their reasonings from one example to another. Not even the scientific response carried over from one context to the other with statistical significance. 1

It should not be forgotten how influential the contextual effect is, given the differences in the phenomena that had been observed before those of repulsion (see the figures of Annex 1). In the case of the electrified transparency and the ball electroscope, there was first an attraction and then a contact prior to the sudden repulsion between the two. The fact is that many students replied by drawing charges of the same sign on the transparency and the electroscope bob in order to explain the repulsion. But in their previous drawings (of the attraction and the contact), those who mistook the initial attraction from electrostatic induction necessarily had to forget the principle of charge conservation.

With respect to the c-n induction, no student used the scientific response for both homologous situations, while their alternative conceptions 'both are charged with different signs' and 'both are neutral polarized' were context independent. The persistence of the former of these alternative conceptions has also been described by Guisasola and Furió (1994) and Pontes and Pro (1998). Given these results, therefore, one can say that these two alternative conceptions have a higher cognitive status than the rest, and thus constitute greater obstacles to the appropriate learning of electrostatic induction.

1 Even though $n\left(1^{*}\right)=14$. This is because this contingency table contains 10 blank responses. If the calculations of $X^{2}$ are repeated taking this into account, the results will be: $66.7 \%, 58.3 \%, 29.9 \%$, a.r. $=2.4$, and $p=0.0081$. 
In the post-test, as was seen in figures 2,3,4, appropriate responses were in the majority for both types of experiment. One can thus say that they were context independent.

Next, the conclusions are drawn in order to answer the last research question and reach one of the main aims of the study: identify the greatest obstacles to learning.

\section{Conclusions}

These status indicators are easy to use by any teacher, because there is only the need to design a test to apply before and after having conducted the corresponding teaching unit. They do not require the teacher to delve into the complexities of multivariate analysis. It is enough to use straightforward descriptive statistics and contingency tables.

In this type of educational research, the aim is obviously not to establish general conclusions, but, by allowing comparisons with other similar studies, to contribute to greater understanding of the obstacles to student learning, and to improving the strategies to overcome them.

The inventory of ideas shown by our results with prospective primary teachers is consistent with those obtained by Furió and Guisasola (1993), Furió, Guisasola and Zubimendi (1998); Guisasola and Furió (1994), Guisasola (1999), and Pontes and Pro (1998) whose work on electrostatics was with students of pre-university secondary education, schools of engineering, and prospective secondary school teachers. The present study complements their work not only because of the different educational level which it involved, but also because we looked for the existence of different explanations in the cognitive structure of the same individual (Taber, 2000), i.e., different reasonings that may be activated in contexts that are scientifically homologous and that consequently should have a single interpretation.

We will report the conclusions answering the questions addressed in the study.

\section{Before the teaching sequence}

The prior ideas that compete with the scientific answer are:

- For charged body attractions, one alternative conception: 'they are both neutral and polarized, with charges of different sign facing each other in the two objects, $|+-|+-\mid$ '.

- For charged body repulsions, the alternative conceptions:

○ 'both are neutral polarized, with charges of the same sign opposite each other', $|+-|$ $1-+\mid$ '.

○ 'both are neutral without polarization, and that neutral state is what makes them repel each other' since 'if they were charged they would attract each other'.

- For electrostatic induction between a charged body and a neutral body,

as it is mistaken for a c-c attraction, one has:

○ 'they are both charged, with charges of different sign|'.

○ 'they are both neutral and polarized, with charges of different sign facing each other in the two objects, $|+-||+-|$ '.

Before the teaching sequence, the students' certainty is low, relatively few students were 'quite sure' about any of their reasoning (whether scientific or intuitive). This similar plausibility confirms the similarity in status and the rivalry between the scientific and the alternative explanations.

The degree of context dependence shows that students tend to maintain their answers 
(adequate or inadequate) when they are set an homologous electrostatic attraction to explain. But they tend to change their reasoning if what they observe is a repulsion. In an attraction due to c-n induction, the alternative conceptions are especially stable when the example is changed.

During the planned teaching-learning sequence

The evolution from prior ideas to adequate scientific knowledge is easily achieved (although repulsions seem to be more difficult at the beginning) if attractions and repulsions between two charged bodies are dealt with in parallel.

The teaching activities about electrostatic induction produce diverse results. Repeating the 'ball-point pen/paper' and the 'transparency/paper' experiments, and electrifying a person by the influence of a nearby generator, were quite successful activities. There was little success, however, with the leaf electroscope or the pencil-and-paper task of the electrostatic influence of a storm cloud.

\section{Which ideas are most resistant to change after the teaching sequence?}

After the teaching-learning sequence, some prior ideas remain, but with low plausibility and few students involved. For two charged bodies, these alternative conceptions usually were of interactions between two neutral but polarized objects. The drawings were reminiscent of permanent dipole molecules with a particular orientation (or with a 'sort' of polarization), depending on what had to be explained (an attraction or a repulsion). There were similar prior ideas in the explanation of electrostatic induction, and the mistaken belief that it is a case of an attraction between two charged bodies.

Overall, the information reported above leads us to conclude that, of the three types of electrostatic interactions studied, the physical explanation of the attraction between charged bodies was the easiest for them to learn. Electrostatic repulsions are not easily explained intuitively. The advantage is, however, that the scientific explanation faces no real competition from any high status intuitive conception, so it is easy to modify the inadequate ideas.

Induction was that which generated alternative conceptions with the highest status. Nonetheless, as argued by Taber (2000), the possible existence of multiple frameworks in the mind of a given individual opens a path towards a restructuring of concepts, a search for better explanations, and hence towards the construction of appropriate scientific knowledge.

In short, two particular difficulties stood out:

- A meta-conception: when two bodies interact, there necessarily has to be a certain 'symmetry' (both charged or both neutral). So, if the observed effect is an attraction, no difference is considered in explaining $\mathrm{c}-\mathrm{c}$ attraction and $\mathrm{c}-\mathrm{n}$ induction.

- Mistaking 'charged objects' for 'neutral and polarized' objects.

This study grew out of action research over several academic courses, including previous exploratory studies which provided the grounds for the definitive research design and working hypothesis. Having discussed the conclusions to be drawn from the study, we may now indicate some implications of these results for teaching.

\section{IMPLICATIONS}

Within a teaching sequence, experiments such as those with charged strips of adhesive tape can satisfy the theoretical expectations of the students who can verify that their predictions are fulfilled. The experiment of electrifying the same plastic pen with two types of fabric 
selected for the plastic to acquire a charge of a different sign may help to rebut the preconception that 'there are materials inherently charged with charge of a given sign'.

With respect to the explanations of electrostatic induction in a neutral body by a charged body, the status indicators suggested that the idea that 'when two objects attract each other, they are necessarily charged with charges of different sign' may be firmly rooted. This obstacle can come back when using an electroscope.

It was also noteworthy that familiarity with an experiment that recurs in teaching and in textbooks does not seem to help with its interpretation. In particular, we are referring to the experiment of a pen charged by rubbing it that attracts thin pieces of paper by electrostatic induction. Presented together with another set of simple experiments, this accumulated the highest rates of blank responses and the lowest rates of appropriate explanations.

The same situation has been described (Taber, 2008) for the experiment of a balloon charged by rubbing which sticks to the wall (very common as a party trick for children, but rarely dealt with in class). In that study, a student who knew what electrostatic induction meant at the atomic level had difficulty in recognizing this as being an everyday case of the phenomenon.

Hence we conclude that for experiments to fulfil their function of facilitating the learning of abstract concepts such as the electrical behaviour of matter, we as teachers will have to devote the necessary attention to these experiments for our students to be able to apply the concepts involved. There has to be group discussion of the different responses obtained in a pre-test of prior ideas. And to ensure the appropriate interpretation, we suggest that the empirical experiment should always be accompanied by a pencil-and-paper task. In this, the students should sketch the electric charges that correspond to each phase (neutral objects to start with, then the process of electrification and charge transfer, induction and polarization, etc.), and write brief descriptions of what is shown in the illustrations.

Nevertheless, the interpretation of induction experiments in which the students observe attractions between the bodies suffers from the difficulty that this attraction may be the only observation that the students take into account in their reasoning. Anticipating this obstacle, as teachers we must draw the students' attention to the rest of the facts that are observed emphasizing that only one of the bodies has been subjected to any treatment (to electrify it), while the other has not been touched.

Similarly, we observed that reflection on activities that require the students' active involvement increases their interest in trying to explain the phenomena they observed. This was the case with the electrification by induction of a student standing close to the van de Graaff generator. There was clearly visible evidence of the electrification in her hair, and there was the game-playing character of her being discharged with a spark when a colleague was touched.

Motivational activities are not always conducive to success, as we observed with the example of how the leaf electroscopes (that the students themselves constructed) work.

Although experiments have an important role to play in illustrating with examples the construction of concepts, the teacher's guidance is indispensable. In our case, the teacher's interventions were fundamental in the class debates in which the students presented their different interpretations of rules that they had assimilated very strongly, such as 'like charges repel'. The teacher should insist on such apparently simple expressions being accompanied by a drawing of what the student understands by 'equal charges', of how the charges got to the object, and of the meaning of the labels 'charged' and 'polarized'.

The teacher's metacognitive intervention is also needed to break the spontaneous tendency to interpret interactions in terms of dichotomies or symmetrical situations. In particular, the 
students need to see that there can be electrostatic attraction between objects in a situation of asymmetry - one charged, the other neutral.

Our results indicate that, for short-term learning, an effective teaching strategy is posing questions and inviting the students to solve them with the aid of a dossier designed specifically for that purpose, and with the teacher's guidance. As the students come up with responses to each question, they should be invited to be aware of how plausible they really find them, i.e., how certain they feel about them. This methodological approach will encourage them to verify their hypotheses by argument and appropriate experiments, to go back over the ideas that were expressed in the previous class, reinforcing them, or perhaps even questioning their validity and generating a demand for sessions of recapitulation and reflection on what apparently had been learnt.

But there is still a long way to go. One needs to determine not only what the best practical approach in the classroom is, but also how much periodic and cyclic learning time would be required to produce satisfactory and steady evolution of the students' ideas. Therefore, there remains to address the question that, if these are the results following a short-term teaching process, what will be the case in the longer term?

\section{REFERENCES}

AIP (American Institute of Physics) (1998). Children's misconceptions about Science.

"Operation Physics", elementary-middle school physics education project. Retrieved September 26, 2008, from: http://www.amasci.com/miscon/opphys.html

Brincones, I. \& Otero J. (1994). Students' conceptions of the top-level structure of physics texts. Science Education, 78(2), 171-183.

Buty, C., Tiberghien, A. \& Le Maréchal, J.F. (2004). Learning hypotheses and an associated tool to design and analyse teaching-learning sequences. International Journal of Science Education, 26(5), 579-604.

Cañal, P. (1999). Investigación escolar y estrategias de enseñanza por investigación. Investigación en la Escuela, 38, pp. 14-36.

Carrascosa, J. (2005). El problema de las concepciones alternativas en la actualidad (parte II). El cambio de concepciones alternativas. The problem of alternative conceptions nowadays (part II). Changing alternative conceptions. Revista Eureka sobre Enseñanza y Divulgación de las Ciencias (2005), 2(3), 388-402. Available at http://www.apac-eureka.org/revista.

\section{(Last retrieved May 10, 2009)}

Charrier, M., Cañal, P. \& Rodrigo, M. (2006). Las concepciones de los estudiantes sobre la fotosíntesis y la respiración: una revisión sobre la investigación didáctica en el campo de la enseñanza y el aprendizaje de la nutrición de las plantas. Enseñanza de las Ciencias, 24(3), 401-410.

Criado, A.M. (2000). Un estudio didáctico en torno a la enseñanza de aspectos básicos de la electrostática en la formación inicial de maestros. A didactic study of teaching basic aspects of electrostatics in teacher training. Unpublished PhD thesis. U. de Sevilla. (Abstract in Enseñanza de las Ciencias 2002, 20(1) 182-183 and http://www.naturfagsenteret.no/esera/phd/abstract81.html (Last retrieved May 10, 2009)

Criado, A.M. \& Cañal, P. (2000). La estructuración del conocimiento escolar: el caso de la electrostática. Structuring school science knowledge. The case of Electrostatics. In Martín M. \& Morcillo J.G. eds. Reflexiones sobre la didáctica de las ciencias Experimentales. pp. 532-540. Madrid: Nívola. 
Criado, A.M. \& Cañal, P. (2002a). La identificación de fenómenos electrostáticos cotidianos por estudiantes de magisterio. Identification of everyday electrostatic phenomena by student Primary teachers. Alambique, 32, 32-38.

Criado, A.M. \& Cañal, P. (2002b). Obstáculos para aprender conceptos elementales de electrostática y propuestas educativas. Obstacles to learning elementary Electrostatics concepts and educational proposals. Investigación en la Escuela, 47, 53-63.

Criado, A.M. \& Cañal, P. (2003). Investigación de algunos indicadores del estatus cognitivo de las concepciones sobre el estado eléctrico. Research on indicators of the cognitive status of conceptions about electric state. Enseñanza de las Ciencias $n^{\circ}$ extra 29-41.

Criado, A.M, Morón, M.C., Venero, C. \& Martínez, L.I. (1997). Actividades para aprender electrostática. Fichas didácticas. Activities to learning Electrostatics. Educational booklets. Sevilla: C. Venero, ed.

Driver, R., Guesne, E. \& Tiberghien, A. (Eds.) (1992, 2ª ed.). Ideas cientificas en la infancia y en la adolescencia. (Children's ideas in science) /Madrid: MEC/ Morata.

Feynman, R., Leighton, R.B. \& Sands, M. (1987). Física. Vol. II. Electromagnetismo y materia. México, D.F.: Addison-Wesley Iberoamericana.

Fischer, H.E. \& von Aufschnaiter, S. (1993). Development of meaning during physics instruction: Case studies in view of the paradigm of constructivism. Science Education, 77(2) 153-168.

Furió, C. \& Guisasola, J. (1993). ¿Puede ayudar la historia de la ciencia a entender por qué los estudiantes no comprenden los conceptos de carga y potencial eléctricos? Can Science History help to clarify why students cannot understand electric charge and potential? Revista Española de Física, 7 (3) pp. 46-50.

Furió, C. \& Guisasola, J. (1998). Dificultades de aprendizaje de los conceptos de carga y campo eléctrico en estudiantes de Bachillerato y Universidad. A-Level and university students learning difficulties of electric charge and field Enseñanza de las Ciencias, 16(1), 131-146.

Furió, C. \& Guisasola, J. (1999). Concepciones alternativas y dificultades de aprendizaje en electrostática. Selección de cuestiones elaboradas para su detección y tratamiento. Alternative conceptions and learning difficulties on Electrostatics. Questions selection made for its detection and treatment. Enseñanza de las Ciencias, 17(3), 441-452.

Furió, C., Guisasola, J., Almudí, J.M. \& Ceberio, M. (2003). Learning the electric field concept as oriented research activity. Science Education, 87, 640-662

Furió, C., Guisasola, J. \& Zubimendi, J. L. (1998). Problemas históricos y dificultades de aprendizaje en la interpretación newtoniana de fenómenos electrostáticos considerados elementales. Historical problems and learning difficulties on Newtonian interpretation of electrostatic phenomena . Investigações em Ensino de Ciências, 3(3), 165-188. Retrieved September 26, 2008, from: http://www.if.ufrgs.br/public/ensino/revista.htm

Guisasola, J. (1999). Enseñanza/aprendizaje de la teoría eléctrica que explica los fenómenos electrostáticos básicos. Teaching/learning of electric theory that explains basic electrostatic phenomena . Alambique, $\mathrm{n}^{\circ}$ 19, 9-18.

Guisasola, J. \& Furió, C. (1994). Dificultades en el aprendizaje significativo de algunos conceptos de Electrostática. Difficulties on significative learning of some electrostatic concepts. Investigación en la Escuela, 23, 103-114.

Heering, P. (2000). Getting shocks: Teaching secondary school physics through history. Science \& Education, (9) 363-373. 
Hetch, E. (1987). Física en perspectiva.Physics in perspective. México, D.F.: AddisonWesley-Iberoamericana.

Hewson, P.W., Beeth, M.E. \& Thorely, N.R. (2003). Teaching for conceptual change. International Handbook of Science Education II. Dordrecht. The Netherlands: Kluwer Academic Publishers.

Hewson, P.W. \& Thorely, N.R. (1989). The conditions of conceptual change. International Journal of Science Education, 11, special issue, pp. 541-553.

Jiménez-Aleixandre M.P. (1992). Thinking about theories or thinking with theories? A classroom study with natural selection. International Journal of Science Education, 14, 5161

Keevs, J.P. (2003). Methods and processes in research in science education. In International Handbook of Science Education II. Dordrecht. The Netherlands: Kluwer Academic Publishers.

Leach, J. \& Scott, P. (2002). Designing and evaluating science teaching sequences: an approach drawing upon the concept of learning demand and a social constructivist perspective on learning. Studies in Science Education, 38, 115-142.

Lee, V. (ed.) (2004). Teaching and learning through inquiry: A guidebook for institutions and instructors. Sterling, Virginia: Stylus Publishing LLC.

Lee, E. and Luft, J.A. (2008). Experienced Secondary Science Teachers' Representation of Pedagogical Content Knowledge. International Journal of Science Education, 30(10), 1343 1363.

Lijnse, P. \& Klaassen, K. (2004). Didactical structures as an outcome of research on teachinglearning sequences? International Journal of Science Education, 26(5), 537-554.

Matthews, M.R. (1990). History, Philosophy and Science Teaching: A rapprochement. Studies in Science Education, 18, 25-51.

McMillan III, C. \& Swadener, M. (1991). Novice use of qualitative versus quantitative problem solving in electrostatics. Journal of Research in Science Teaching, 28 (8) 661 670.

Meneses, J.A. \& Caballero, M.C. (1995). Secuencia de enseñanza sobre electromagnetismo Electromagnetism teaching sequence. Enseñanza de las Ciencias, 13, (1), 36-45.

Monk, M. (1995). On the identification of principles in science that might inform research into students' beliefs about natural phenomena. International Journal of Science Education, 17(5), 565-573.

Moore, G.S.M. (1991). Problem: Leaf electroscope. Physics Education 23(3)181,199.

Nilsson, P. (2008).Teaching for Understanding: The complex nature of pedagogical content knowledge in pre-service education. International Journal of Science Education, 30(10), 1281-1299.

Oliva, J. M. (1997). Estatus de las concepciones de los estudiantes en Física: un proyecto de investigación en curso. Status of students' conceptions on Physics: an ongoing research project . Enseñanza de las Ciencias $\mathrm{n}^{0}$ extra V Congreso Internacional sobre Investigación en la Didáctica de las Ciencias. Murcia, 203-204.

Oliva, J. M. (1999a). Algunas reflexiones sobre las concepciones alternativas y el cambio conceptual Some reflections about alternative conceptions and conceptual change. Enseñanza de las Ciencias, 17 (1). 93-07.

Oliva J.M. (1999b). Structural patterns in students' conceptions in mechanics. International 
Journal of Science Education, 21, (3,) pp. 903-920.

Padilla, K. \& Furió-Mas, C. (2008). The Importance of History and Philosophy of Science in Correcting Distorted Views of 'Amount of Substance' and 'Mole' Concepts in Chemistry Teaching. Science \& Education, 17(4), 403-424.

Palmer, D. (1997). The effect of context on students' reasoning about forces. International Journal of Science Education, 681-696.

Park, J. (2001). Analysis of students' processes of confirmation and falsification of their prior ideas about electrostatics. International Journal of Science Education, 23, (12) 1219-1236.

Pontes, A. (1999). Aportaciones al estudio de las concepciones sobre electromagnetismo y sus implicaciones en la Didáctica de la Física. Contributions to the study of Electromagnetism conceptions and its implications in science Education. Unpublished $\mathrm{PhD}$ thesis. Universidad de Córdoba.

Pontes, A. \& Pro, A. (1998). Interacciones eléctricas y estructura de la materia: dificultades de los estudiantes en la adquisición de modelos científicos. Electric interactions and matter structure: students difficulties acquiring scientific models . In E. Banet \& A. de Pro (Coords.) Investigación e innovación en la Enseñanza de las Ciencias. Murcia: Publicaciones Universidad de Murcia. 293-310

Porlán, R. \& Martín del Pozo, R. (2002). Spanish teachers' epistemological and scientific conceptions: Implications for teacher education. European Journal of Teacher Education, 25(2), 151-169.

Pfund \& Duit, R. (1998). Bibliography: Student's alternative framework and science education. Edited by IPN, Institute for Science Education, Kiel, Germany.

Sánchez Carrión, J.J. (1995). Manual de análisis de datos. Data analysis manual. Madrid: Alianza U. Textos.

Seroglou, F., Komouras, P. \& Tselfes, V. (1998). History of science and instructional design: the case of electromagnetism. Science \& Education, 7, 261-280.

Shulman, L.S. (1989). Those who understand: Knowledge growth in teaching. Educational Research, 15 (2), 4-14.

Solbes J. \& Martín, J. (1991). Análisis de la introducción del concepto de campo. Analysing the concept of field introduction . Revista Española de Física, 5(3), 34-39.

Taber, K.S. (2000). Multiple frameworks? Evidence of manifold conceptions in individual cognitive structure. International Journal of Science Education, 22 (4), 399-417.

Taber, K. (2002). Chemical Misconceptions: Prevention, Diagnosis and Cure. London, UK: Royal Society of Chemistry.

Taber, K.S. (2008). Exploring conceptual integration in student thinking: Evidence from a case study. International Journal of Science Education, 1-29. iFirst Article.

Teichert, M.A., Tien, L.T., Anthony, S. \& Rickey, D. (2008). Effects of Context on Students' Molecular-Level Ideas. International Journal of Science Education, 30(8), 1095-1114.

Tao, P-J, (2001). Developing understanding through confronting varying views: the case of solving qualitative physics problems. International Journal of Science Education, 23 (2), 1201-1218.

Tiberghien, A., Leonard, E. \& Barojas, J. (Eds.) (1997, 1998). Connecting Research in Physics Education with Teacher Education. International Commission on Physics Education [ICPE]. Retrieved September 26, 2008, from: http://www.physics.ohiostate.edu/ jossem/ICPE/TOC.html 
van Driel, J.; Verloop, N. \& de Vos, W. (1998). Developing science teacher's pedagogical content knowledge. Journal of Research in Science Teaching, 35(6), 673-695.

Wood-Robinson, C. (1995). Children's biological ideas: Knowledge about ecology, inheritance, and evolution. In S.M. Glynn y R. Duit (Eds.), Learning science in the schools: Research reforming practice (111-130). Mahwah, NJ: Lawrence Erlbaum Associates. 


\section{APPENDICES}

\section{Annex 1: Questions of the two homologous tests}

\section{A) Questions of the type X test}

1.Two strips of adhesive tape are cut and stuck to each other by superimposing the face with glue of one to the unglued face of the other. They are then pulled apart and held at a certain distance from each other, observing that they attract. What is the physical interpretation of this attraction? Illustrate your explanation by completing the picture with electric charges.

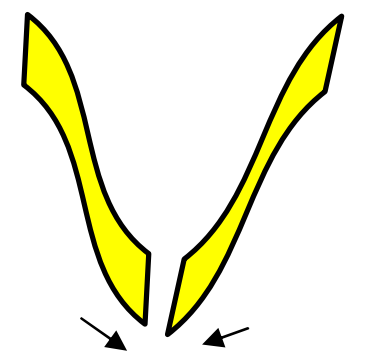

Completely sure Fairly sure Somewhat sure Undecided Not at all sure

2. Two recently cut strips of adhesive tape are brought up close to each other. One observes that they repel. What is the physical interpretation of this repulsion? Illustrate your explanation by completing the picture with electric charges.

Completely sure Fairly sure $\quad \stackrel{5}{\leftarrow}$ Somhat sure $\quad \longrightarrow$ Undecided Not at all sure

3. A plastic ball-point pen is rubbed with a piece of lining fabric and brought up close to some pieces of paper. It attracts them. How can this attraction be explained? Illustrate your explanation by completing the picture with electric charges.

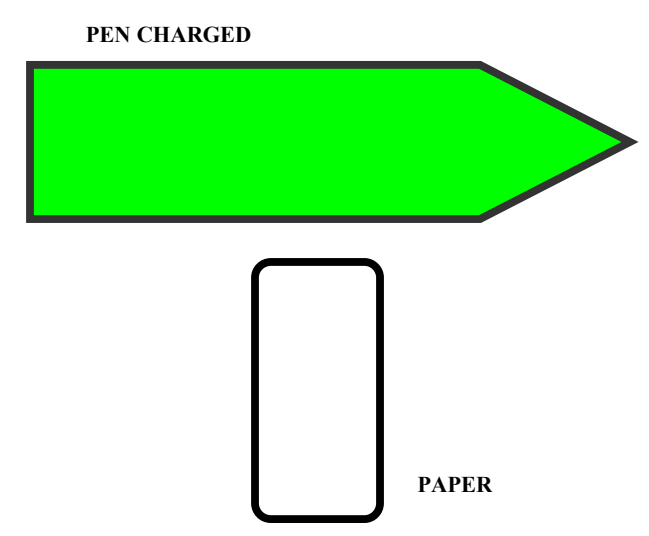

Completely sure Fairly sure Somewhat sure Undecided Not at all sure 


\section{B) Questions of the type $Y$ test}

1.A transparency is pressed or rubbed against a sheet of paper. They are separated and held at a certain distance from each other, observing that they attract. What is the physical interpretation of this attraction? Illustrate your explanation by completing the picture.

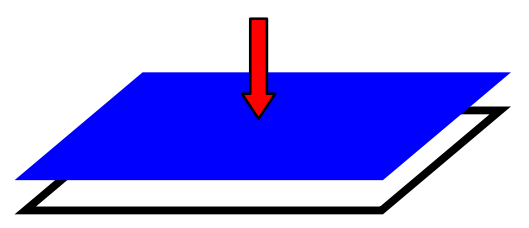

Completely sure Fairly sure Somewhat sure Undecided Not at all sure

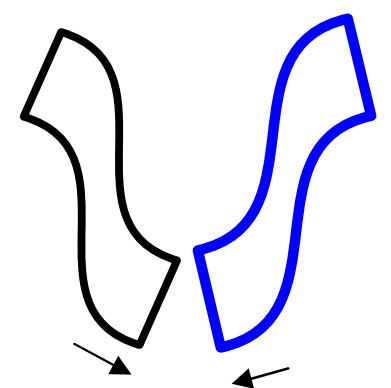

2. A transparency is pressed against a sheet of paper. It is then brought close to the ball electroscope which it attracts. How can this attraction be explained? Write a sentence and complete the picture for the transparency and the ball electroscope to illustrate the explanation.
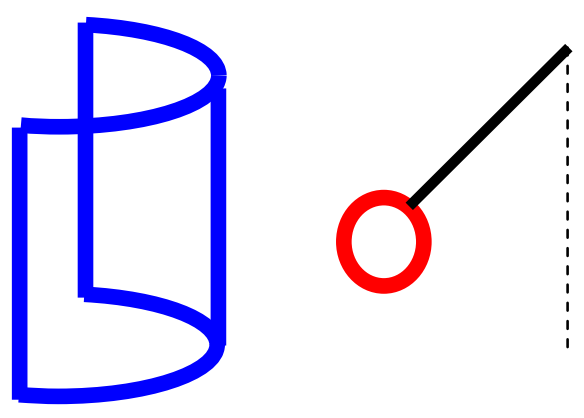

Completely sure Fairly sure Somewhat sure Undecided Not at all sure

3. The transparency of the previous question is made to come into contact with the ball electroscope, which it now repels. What is the physical interpretation of this repulsion? Illustrate your explanation by completing the picture.
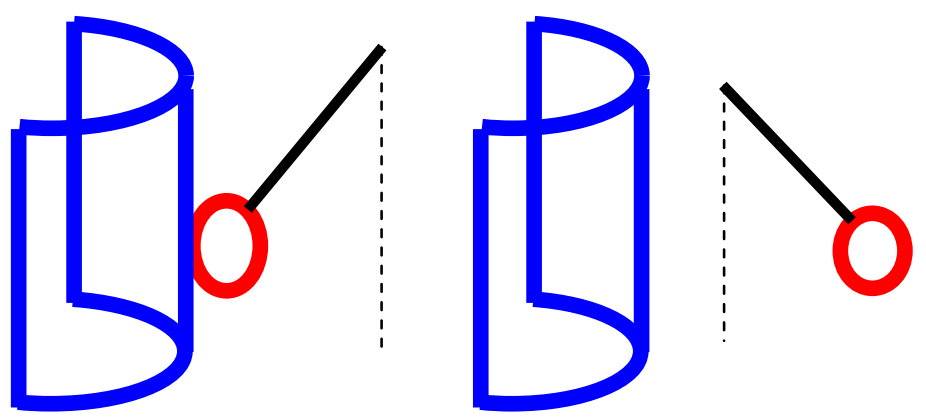

Completely sure Fairly sure Somewhat sure Undecided Not at all sure 


\section{Annex 2. Some features of the teaching unit and its implementation}

The questions that formed the backbone of the teaching unit were of two types: descriptive, such as the first three presented below, or interpretive, such as the rest:

* What do we know about electric interactions? Why are they important?

* In the experiments with charged objects, we observed attractions and repulsions. What might this suggest with respect to the types of electric charges that exist? What might be the rule which governs these interactions?

* After two objects have been in firm contact, it is noted that they attract each other (for example, the transparency and the sheet of paper. What might this suggest about the type of electricity they have each acquired?

* Among the interactions known in Nature, where is the electric force situated?

* What factors does the value of the electric force depend on? And, quantifying the interaction, of what order of magnitude are the forces and charges in known phenomena?

* What is electric charge? What exactly is meant by 'being charged' or 'being neutral'?

* What does the process of contact electrification consist of?

* What are the differences in the behaviour of an electrical conductor and an insulator?

* Do two objects have necessarily to be charged for them to attract each other?

* Is it necessary for there to be contact with a conductor to electrify it? How many ways are there to electrify an object?

In each block of activities, one of the tasks to be performed was that each group repeated the introductory experiments, and discussed all the responses given by the class to the pre-test. Also, each group carried out new experiments on the topic dealt with in that block. The following are some of the empirical activities and tasks in the teaching sequence that complemented the initial experiments.

1) Design a procedure to determine the sign of the charge of objects electrified. Material suggested: pith-ball electroscope, sheet of glass, vinyl disk, ball-point pens, and lining fabrics of $100 \%$ polyester and of $100 \%$ cotton. Construct a table indicating the sign of the charge acquired and the object electrified. Check specifically: (a) whether the glass and the disk acquire the same charge when they are rubbed with the lining fabric; (b) whether the ballpoint pen acquires the same type of charge when it is rubbed with $100 \%$ polyester fabric and with $100 \%$ cotton fabric. Reference datum: The TV screen and the vinyl acquire a '-' charge.

2) Give your hypotheses about how the homemade leaf electroscope that you constructed detects electric charge, drawing the charges on it. Check them, and present the results in a table.

3) Interpret the following experimental observations of the class when the Van der Graaf generator was used:

- A person close to the generator perceives nothing anomalous, but if he touches another he notices a spark.

- If the person close to the generator has long fine hair, some hairs in front of the sphere stand up pointing towards it.

Illustrate your explanation drawing electric charges on the sphere of the generator and on the person in the picture.

4A) Apply your knowledge of induction to explain why, when a charged object is brought up 
close to a neutral leaf electroscope, its leaves open up and close again when the object is taken away. Draw how the charges would be distributed in the electroscope.

4B) Check it experimentally with your electroscope. (Remember that there should be no contact between a charged body and the electroscope, so that if near to it you hear sounds of electric sparks, you must interpose an insulator - a transparency - to avoid them.)

5) Apply what you know to give a preliminary explanation of how a lightning rod works. (The explanation with 'electric field' and 'tip effects' will be seen in the next topic.) Draw a tree beneath a negatively charged storm cloud. Draw the charges on the tree, and write a sentence describing the effect of the cloud, using the ideas of 'induction' and 'grounded conductor'. In a second step, use the ideas of 'concentration of charge on the tips' and 'dielectric strength of a gas' (as in the experiment of the fluorescent tube) to explain lightning. 